\title{
VARIABILIDADE ESPACIAL DOS TEORES DE MACRONUTRIENTES EM LATOSSOLOS SOB SISTEMA PLANTIO DIRETO ${ }^{(1)}$
}

\author{
Luiz Antônio Zanão Júnior ${ }^{(2)}$, Regina Maria Quintão Lana ${ }^{(3)}$, \\ Ednaldo Carvalho Guimarães ${ }^{(4)}$ \& Josefa Monteiro de Araújo
}

Pereira $^{(5)}$

\begin{abstract}
RESUMO
A eficácia dos planos de amostragem do solo pode ser aumentada se for conhecida e considerada a variabilidade espacial de seus atributos, e, para isso, devem ser estudados os fatores que a determinam. O objetivo deste trabalho foi avaliar a variabilidade espacial dos teores de macronutrientes $\mathrm{P}, \mathrm{K}, \mathrm{Ca}, \mathrm{Mg}$ e S em dois Latossolos, um muito argiloso e outro de textura média, cultivados com manejo semelhante, há oito anos sob sistema plantio direto. A coleta das amostras do solo foi realizada em intervalos regulares de $50 \mathrm{~m}$, totalizando 121 pontos, em duas camadas (0-10 e 10-20 cm). Os dados foram avaliados por estatística descritiva e geoestatística, com base no ajuste de semivariogramas. Verificou-se que a dependência espacial varia conforme o elemento, a textura do solo e a profundidade de coleta da amostra. Assim, o Latossolo de textura média, de maneira geral, apresentou maior variabilidade espacial para os teores dos nutrientes em relação ao de textura muito argilosa. A camada de 0-10 cm, nos dois Latossolos, proporcionou maior variabilidade espacial para os teores dos nutrientes avaliados. A análise de dependência espacial mostrou que, nos dois solos e nas duas camadas, a maioria dos nutrientes estudados apresentou moderada correlação espacial. Os modelos de semivariogramas ajustados foram o exponencial e o esférico, sendo o primeiro em maior quantidade. Maiores teores de todos os macronutrientes avaliados foram verificados nos primeiros $10 \mathrm{~cm}$ do solo. Os valores de alcance da dependência espacial foram menores no Latossolo de textura média, variando de 9 a $29 \mathrm{~m}$; no de textura muito argilosa eles variaram de 31 a $399 \mathrm{~m}$. Se for adotada
\end{abstract}

\footnotetext{
(1) Parte da Monografia do Curso de Graduação do primeiro autor. Recebido para publicação em fevereiro de 2009 e aprovado em

(2) Pesquisador do Instituto Agronômico do Paraná - IAPAR. Pólo Regional de Pesquisa de Ponta Grossa. Rodovia do Café, km 496, Av. Pres. Kennedy s/n, Caixa Postal 129, CEP 84001-970 Ponta Grossa (PR). E-mail: lzanao@iapar.br

(3) Professora do Instituto de Ciências Agrárias, Universidade Federal de Uberlândia - UFU. Caixa Postal 593, CEP 38400-902 Uberlândia (MG). E-mail: rmqlana@iciag.ufu.br

(4) Professor da Faculdade de Matemática, UFU. E-mail: ecg@ufu.br

(5) Engenheira-Agrônoma, Rua Santos Dumont, 1455, CEP 84010-366 Ponta Grossa (PR). E-mail: meiry_pereira@yahoo.com.br
} 
a geoestatística no esquema de amostragem, o número de amostras a serem coletadas será menor no Latossolo de textura muito argilosa, devido aos maiores valores do alcance apresentados por todas as variáveis.

Termos de indexação: geoestatística, fertilidade do solo, semivariograma, amostragem.

\title{
SUMMARY: SPATIAL VARIABILITY OF MACRONUTRIENT CONTENTS IN UNTILLED OXISOLS
}

\begin{abstract}
The effectiveness of soil sampling plans may be increased if the spatial variability of soil properties is known and taken into consideration; the factors that determine it should therefore be studied. The objective of this paper was to evaluate the spatial variability of the contents $P, K, C a, M g$, and $S$ in two Oxisols, one very clayey and the other with medium texture, managed in a similar system for eight years, in no-tillage. Soil samples were collected at regular distances of $50 \mathrm{~m}$, totaling 121 points in two layers $(0-10$ and $10-20 \mathrm{~cm})$. The data were analyzed with descriptive statistics and geostatistics, based on the adjustment of semivariograms. It was found that spatial dependence varies with the nutrient, soil texture and sampling depth. Thus, the spatial variability of the medium texture Oxisol for nutrient levels was generally greater than of the very clayey Oxisol. The spatial variability for nutrient levels was highest in both Oxisols in the 0-10 cm layer. The analysis of spatial dependence showed that the spatial correlation in both soils and both layers was moderate for most nutrients studied. Exponential and spherical semivariogram models were adjusted, the first in greater quantity. Highest amounts of all nutrients were detected in the top $10 \mathrm{~cm}$ of soil. The range of spatial dependence in the medium texture Oxisol was lower (9-29 $\mathrm{m}$ ) than in the very clayey Oxisol (31-399 m). If adopted in a geostatistical sampling scheme, the number of samples to be collected will be lower in the very clayey soil, due to the wider range of all variables.
\end{abstract}

Index terms: geostatistics, soil fertility, semivariogram, sampling.

\section{INTRODUÇÃO}

$\mathrm{Na}$ agricultura atual ainda predomina a aplicação de fertilizantes considerando-se extensas áreas como homogêneas, empregando-se quantidades de acordo com a fertilidade média da área. A análise de solo na qual se baseiam as recomendações de adubação também resulta de amostras coletadas de maneira aleatória. Esse modelo de aplicação de insumos, desconsiderando a variabilidade espaço-temporal, pode levar à aplicação de nutrientes em glebas em que estes já estejam em teores satisfatórios e não suprir a necessidade da cultura para uma alta produtividade em glebas deficientes. Como consequência, ocorre o uso não racional de fertilizantes, o que pode comprometer o rendimento das culturas, onerar o custo de produção e provocar degradação ambiental (Zanão Júnior, 2004). A adoção da agricultura de precisão, que enfoca a variabilidade espacial e temporal das necessidades de aplicação de fertilizantes e outros insumos durante todo o processo produtivo, pode resolver esses problemas (Malzer, 1996).

Uma das maneiras mais utilizadas para representar a variabilidade espacial dos atributos do solo são os mapas de isolinhas (Burgess \& Webster, 1980). No entanto, para construção desses mapas é necessário conhecer a distribuição da variável e seu grau de dependência espacial, sendo a maneira mais usual para isso utilizar a geoestatística (Vieira et al., 1983). Isso permite a obtenção de mapas de fertilidade de solos e da produtividade das culturas e é um importante passo para que se possa empregar um manejo mais adequado, considerando-se a estratégia de amostragem e a aplicação de fertilizantes e, ainda, a combinação dessas informações para que as áreas de uma propriedade sejam gerenciadas de forma localizada (Bhatti et al., 1991; Burrough et al., 1996).

Vários trabalhos mostram que os sistemas conservacionistas de manejo criam no solo um ambiente diferente do encontrado no sistema convencional. A variabilidade espacial dos índices de fertilidade do solo aumenta com a adoção do sistema plantio direto, tanto no sentido vertical quanto no horizontal (Eltz et al., 1989; Souza, 1992; Amaral \& Anghinoni, 2001). Nesse sistema, o acúmulo e a qualidade dos diferentes materiais de cobertura produzidos nos vários sistemas de sucessão e rotação de culturas adotados, o não revolvimento do solo e as frequentes adubações e calagens em superfície e nas linhas de cultivo formam um gradiente de concentração superficial de matéria orgânica e nutrientes, aumentando tanto a variabilidade vertical 
quanto a horizontal (Muzilli, 1983; Eltz et al., 1989; Klepker \& Anghinoni, 1995).

A variabilidade do solo também é uma consequência de complexas interações dos fatores e processos de sua formação, podendo variar de acordo com as culturas e seu manejo. Áreas pedologicamente similares podem apresentar diferença na variabilidade quando submetidas a diferentes práticas de manejo, e áreas pedologicamente diferentes, quando submetidas ao mesmo manejo, podem apresentar atributos semelhantes (Corá et al., 2004). Montanari et al. (2008), estudando solos com manejos similares em áreas cultivadas com cana-de-açúcar em diferentes pedoformas, verificaram que o Latossolo inserido na pedoforma convexa apresentou maior variabilidade espacial para os atributos químicos em relação ao Argissolo na pedoforma linear. A variabilidade espacial da textura do solo foi avaliada em várias classes de solos e constatou-se que ela apresenta dependência espacial (Souza et al., 1997; Salviano et al., 1998; Corá et al., 2004). Dessa forma, deve ser avaliado se a variabilidade espacial desse atributo físico interfere na dependência espacial dos atributos químicos do solo.

Segundo Orlando Filho \& Rodella (1983), aproximadamente 80 a $85 \%$ do erro total nos resultados usados na recomendação de fertilizantes e corretivos é decorrente da amostragem no campo, sendo o restante atribuído a equívocos em análises no laboratório. Essa constatação gera a necessidade de se conhecer a variabilidade de cada elemento, de acordo com o manejo do solo, a profundidade de coleta, entre outros fatores que a possam influenciar, e traçar um plano amostral adequado, segundo essa variabilidade individual. Assim, alguns nutrientes necessitam de números maiores de amostras que outros para que se possa conhecer o seu comportamento em relação a uma determinada área. Então, o objetivo deste trabalho foi avaliar a variabilidade espacial dos macronutrientes $\mathrm{P}, \mathrm{K}, \mathrm{Ca}, \mathrm{Mg}$ e $\mathrm{S}$ em dois Latossolos com texturas diferentes, um muito argiloso e outro de textura média, cultivados com manejo semelhante há oito anos em sistema plantio direto.

\section{MATERIAL E MÉTODOS}

Foram amostradas duas áreas, ambas no município de Uberlândia, Minas Gerais. A primeira, Fazenda Santa Rosa (FSR), está localizada entre as coordenadas geográficas de $18^{\circ} 55$ ' de latitude sul e $48^{\circ} 16^{\prime}$ 'de longitude oeste, com altitude média de 860 m. A segunda, Fazenda São Luiz de Jaborandi (FSLJ), localiza-se entre as coordenadas geográficas de $19^{\circ} 06$ ' de latitude sul e $48^{\circ} 51$ ' de longitude oeste e altitude média de $650 \mathrm{~m}$. As duas propriedades possuem solo classificado como Latossolo Vermelho distrófico típico. A diferença está no teor de argila no solo de ambas. Na primeira, o solo é de textura muito argilosa (680 $\mathrm{g} \mathrm{kg}^{-1}$ de argila), e na segunda, de textura média (250 $\mathrm{g} \mathrm{kg}^{-1}$ argila). O relevo das duas propriedades é predominantemente suave ondulado, com declividade média de 3 a $6 \%$. O clima da região, segundo a classificação de Köppen, é Cwa, com estação seca bem definida de maio a setembro e pluviosidade média anual de $1.500 \mathrm{~mm}$. As duas áreas são do mesmo proprietário, sendo manejadas de modo bastante semelhante.

Os sítios de amostragem estão sob cultivo de culturas anuais há mais de 20 anos, e desde 1995 sob sistema plantio direto. A rotação de culturas na área, durante os cinco primeiros anos nesse sistema, foi milho na resteva de soja a partir da safra de 1995/ 1996. Após a colheita do milho safrinha foram utilizados milheto, nabo forrageiro ou aveia-branca como cultura de cobertura, cujas sementes foram semeadas a lanço.

Na implantação do sistema plantio direto, no ano de 1995, foram aplicados e incorporados gesso agrícola e calcário (visando elevar a saturação por bases para $65 \%)$. Nas safras de 1998/99 e 2001/02 houve nova aplicação de calcário, também visando elevar a saturação por bases para $65 \%$. No período de 1996 a 2000, a adubação de semeadura para a cultura da safra de verão (soja ou milho) foi realizada no sulco de semeadura, aplicando-se $140 \mathrm{~kg} \mathrm{ha}^{-1} \mathrm{de} \mathrm{N}, 100 \mathrm{~kg} \mathrm{ha}^{-1}$ de $\mathrm{P}_{2} \mathrm{O}_{5}, 90 \mathrm{~kg} \mathrm{ha}^{-1}$ de $\mathrm{K}_{2} \mathrm{O}$ e $2 \mathrm{~kg} \mathrm{ha}^{-1}$ de $\mathrm{Zn}$. Quando a cultura de verão era a soja, a adubação nitrogenada era suprimida. As culturas de cobertura de solo milheto, nabo forrageiro ou aveia-branca não receberam adubação. Na safra de 2000/2001, a cultura de verão foi a soja, com aplicação de $400 \mathrm{~kg} \mathrm{ha}^{-1}$ do formulado $02-20-18+1 \mathrm{~kg} \mathrm{ha}^{-1}$ de B no sulco de semeadura, Co e Mo no tratamento de sementes e Mn via foliar; na safra de 2001/2002, a cultura de verão foi o milho, com aplicação de $500 \mathrm{~kg} \mathrm{ha}^{-1}$ do formulado 08-28-18 + $6 \mathrm{~kg} \mathrm{ha}^{-1}$ de Zn na semeadura e $120 \mathrm{ha}^{-1}$ de ureia em cobertura (lanço). Na safra de 2002/2003, a cultura de verão foi o algodão, com aplicação de $650 \mathrm{~kg} \mathrm{ha}^{-1}$ do formulado 08-28-16 + $1 \mathrm{~kg} \mathrm{ha}^{-1}$ de Zn no sulco de semeadura.

Em 2003, após a colheita do algodão, em ambas as propriedades, uma parcela de 500 x $500 \mathrm{~m}$ foi dividida, formando-se uma malha com espaçamento regular de $50 \mathrm{~m}$ entre os pontos, resultando um quadrado de 11 linhas e 11 colunas, totalizando 121 pontos amostrados nos cruzamentos da malha. Todos os pontos amostrados foram georreferenciados, sendo retirada uma amostra simples por ponto. As amostras foram retiradas com pá de corte, transversalmente aos sulcos de semeadura e no espaço compreendido entre os pontos médios entre os sulcos, e estratificadas em duas profundidades: 0-10 e 10-20 cm.

As amostras de solo, após serem secas ao ar, peneiradas em malha de $2 \mathrm{~mm}$ de abertura, foram analisadas quimicamente, determinando-se $\mathrm{P}$ e K (Mehlich-1), Ca e Mg trocáveis $\left(\mathrm{KCl} 1 \mathrm{~mol} \mathrm{~L}^{-1}\right)$ e S $\left[\mathrm{Ca}\left(\mathrm{H}_{2} \mathrm{PO}_{4}\right)_{2}, 500 \mathrm{mg} \mathrm{L}^{-1}\right.$ de P em HOAc $\left.2 \mathrm{~mol} \mathrm{~L}^{-1}\right]$, conforme descrito em Embrapa (1997) e Alvarez V. et al. (2001). 
Os resultados foram primeiramente submetidos à análise estatística descritiva, obtendo-se média, mediana, valor máximo, valor mínimo, coeficiente de variação, coeficiente de assimetria e coeficiente de curtose. O teste t de Student, a $5 \%$, foi aplicado para comparação das médias dos atributos entre as profundidades em cada solo.

A dependência espacial dos atributos estudados foi avaliada utilizando-se a geoestatística (Vieira et al., 1983), por meio do cálculo da semivariância e do ajuste dos dados ao semivariograma experimental. Os semivariogramas são representações gráficas entre a semivariância $\gamma(\mathrm{h})$, representada na coordenada y, e uma determinada distância $h$, representada na coordenada x. A semivariância pode ser estimada pela seguinte equação:

$$
\gamma(\mathrm{h})=\frac{1}{2 \mathrm{~N}(\mathrm{~h})} \sum_{\mathrm{i}=1}^{\mathrm{N}(\mathrm{h})}\left[\mathrm{Z}\left(\mathrm{x}_{\mathrm{i}}\right)-\mathrm{Z}\left(\mathrm{x}_{\mathrm{i}}+\mathrm{h}\right)\right]^{2}
$$

em que $\mathrm{N}(\mathrm{h})$ representa o número de pares de valores medidos, $\mathrm{Z}\left(\mathrm{x}_{\mathrm{i}}\right)$ e $\mathrm{Z}\left(\mathrm{x}_{\mathrm{i}}+\mathrm{h}\right)$, separados por um vetor $(\mathrm{h})$. $\mathrm{O}$ gráfico de $\gamma(\mathrm{h})$ versus os valores correspondentes de h é denominado semivariograma.

Os semivariogramas foram ajustados com o software $\mathrm{Gs}^{+}$(Gamma Design Software, 2000). A seleção dos modelos foi realizada com base no maior coeficiente de determinação $\left(\mathrm{R}^{2}\right)$ e na menor soma de quadrados do resíduo (SQR), sendo testados os modelos esférico, exponencial, gaussiano, linear, linear sem patamar e efeito pepita puro. Nos semivariogramas ajustados, foram definidos os seguintes parâmetros: efeito pepita $\left(\mathrm{C}_{0}\right)$, patamar $\left(\mathrm{C}_{0}+\mathrm{C}_{1}\right)$ e alcance da dependência espacial (a). A razão entre o efeito pepita e o patamar $\mathrm{C}_{0} /\left(\mathrm{C}_{0}+\mathrm{C}_{1}\right)$ permite a classificação e a comparação entre atributos do solo. Para analisar o grau de dependência espacial dos atributos em estudo, utilizou-se a classificação proposta por Cambardella et al. (1994), em que os semivariogramas com dependência espacial forte têm razão menor ou igual a $25 \%$, os semivariogramas com dependência espacial moderada possuem razão superior a $25 \%$ e inferior a $75 \%$ e os de dependência fraca possuem razão superior a $75 \%$.

Os mapas de isolinhas foram elaborados utilizandose as informações provenientes dos semivariogramas durante o processo de krigagem na interpolação dos dados. Para geração dos mapas das variáveis em que não foi verificada dependência espacial, foi utilizado o método do inverso do quadrado da distância e não a krigagem.

\section{RESULTADOS E DISCUSSÃO}

Os teores dos macronutrientes no solo foram classificados de acordo com Alvarez V. et al. (1999). Na Fazenda Santa Rosa, Latossolo de textura muito argilosa (FSR), na camada de $0-10 \mathrm{~cm}$, os teores de K disponível foram considerados muito bons, e os dos outros macronutrientes, bons. Na camada de 10$20 \mathrm{~cm}$, os teores de $\mathrm{P}$ e $\mathrm{K}$ disponíveis foram classificados como bons; os de $\mathrm{Ca}$ e $\mathrm{Mg}$ trocáveis, médios; e os de S disponível, baixos. Na Fazenda São Luiz de Jaborandi, Latossolo de textura média (FSLJ), os teores de $\mathrm{P}$ foram considerados médios, e os de $\mathrm{Ca}$, $\mathrm{Mg}$ e S, baixos, nas duas camadas. Os teores de K foram classificados como médios na camada de 0$10 \mathrm{~cm}$ e baixos de $10-20 \mathrm{~cm}$. Isso demonstra que o produtor agiu de maneira equivocada em relação à fertilidade do solo em suas propriedades ao manejá-la de modo semelhante. A mesma quantidade de fertilizante foi aplicada nas duas áreas.

Nota-se que os nutrientes avaliados estão em níveis bons na FSR, ao contrário da FSLJ, que necessita de quantidades maiores de fertilizantes para uma mesma expectativa de produção. Por exemplo, se o milho fosse cultivado para produção de grãos, com uma expectativa de produção superior a 8 t ha-1, seguindo recomendação de adubação de Alves et al. (1999), baseada nos teores de $\mathrm{P}$ e $\mathrm{K}$ disponíveis no solo, na FSLJ haveria necessidade de aplicação de $120 \mathrm{~kg} \mathrm{ha}^{-1}$ de $\mathrm{P}_{2} \mathrm{O}_{5}$ e $80 \mathrm{~kg} \mathrm{ha}^{-1}$ de $\mathrm{K}_{2} \mathrm{O}$. Na FSR, seriam necessários $100 \mathrm{~kg} \mathrm{ha}^{-1}$ de $\mathrm{P}_{2} \mathrm{O}_{5}$ e $60 \mathrm{~kg} \mathrm{ha}^{-1}$ de $\mathrm{K}_{2} \mathrm{O}$, ou seja, apenas adubação de manutenção. Considerando que na safra de 2001/2002, em que foi cultivado milho, foram aplicados $140 \mathrm{~kg} \mathrm{ha}^{-1}$ de $\mathrm{P}_{2} \mathrm{O}_{5}$ e $90 \mathrm{~kg} \mathrm{ha}^{-1} \mathrm{de}$ $\mathrm{K}_{2} \mathrm{O}$, observa-se que essas quantidades estavam acima do recomendado para os dois nutrientes nas duas propriedades; contudo, no caso da FSR, em que os teores de $\mathrm{P}$ e K estão adequados, a quantidade desnecessária aplicada foi maior. Esse recurso gasto sem necessidade com $\mathrm{P}_{2} \mathrm{O}_{5}$ e $\mathrm{K}_{2} \mathrm{O}$ poderia ser empregado em um esquema racional de uso de fertilizantes para elevar a fertilidade do solo da FSLJ e, posteriormente, trabalhar apenas com adubação de restituição nas duas propriedades.

A análise descritiva dos dados, apesar de considerálos espacialmente independentes, tem a função de analisar o comportamento geral deles e identificar algum que possa exercer influência na análise geoestatística. Os resultados dessa análise (Quadro 1) indicaram distribuição normal. Os valores de média e mediana estão próximos para todas as variáveis, demonstrando que os dados não apresentam assimetria acentuada (Quadro 1). Segundo Little \& Hills (1978), quando os valores médios e medianos são semelhantes, os dados apresentam ou se aproximam da distribuição normal.

Com apenas uma exceção, foram observados maiores teores de todos os macronutrientes na camada de $0-10 \mathrm{~cm}$, nos dois locais. Diversos estudos mostraram que no sistema plantio direto o acúmulo de nutrientes, principalmente $\mathrm{P}, \mathrm{K}$, Ca e $\mathrm{Mg}$, ocorre na camada superficial do solo. Essa tendência é explicada pelo não revolvimento do solo nesse sistema, bem como pela aplicação da calagem e pelas frequentes 
Quadro 1. Estatística descritiva para os teores de fósforo, potássio, cálcio, magnésio e enxofre em dois Latossolos com texturas distintas cultivados no sistema plantio direto

\begin{tabular}{|c|c|c|c|c|c|c|c|c|c|c|c|c|c|c|}
\hline \multirow{2}{*}{$\begin{array}{c}\text { Teor } \\
\text { no solo }\end{array}$} & \multicolumn{2}{|c|}{ Média } & \multicolumn{2}{|c|}{ Mediana } & \multicolumn{2}{|c|}{ Mínimo } & \multicolumn{2}{|c|}{ Máximo } & \multicolumn{2}{|c|}{ CV (\%) } & \multicolumn{2}{|c|}{ Assimetria } & \multicolumn{2}{|c|}{ Curtose } \\
\hline & $0-10^{(1)}$ & $\overline{10-20}$ & 0-10 & $\overline{10-20}$ & $0-10$ & $10-20$ & $0-10$ & $10-20$ & $0-10$ & $10-20$ & $0-10$ & $10-20$ & $0-10$ & $10-20$ \\
\hline \multicolumn{15}{|c|}{ Fazenda Santa Rosa - textura muito argilosa } \\
\hline $\mathrm{P}^{(2)}, \mathrm{mg} \mathrm{dm}^{-3}$ & $10,12 \mathrm{a}^{(5)}$ & $9,92 \mathrm{~b}$ & 8,30 & 8,30 & 3,30 & 2,10 & 26,60 & 24,10 & 65,70 & 52,12 & 1,12 & 0,88 & 0,54 & $-0,27$ \\
\hline $\mathrm{K}^{(2)}, \mathrm{mg} \mathrm{dm}^{-3}$ & $125,10 \mathrm{a}$ & $70,76 \mathrm{~b}$ & 122,30 & 68,00 & 35,80 & 32,80 & 200,70 & 144,4 & 29,77 & 31,79 & 0,08 & 0,83 & $-0,62$ & 0,45 \\
\hline $\mathrm{Ca}{ }^{(3)}, \mathrm{cmol}_{\mathrm{c}} \mathrm{dm}^{-3}$ & $2,65 \mathrm{a}$ & $1,79 \mathrm{~b}$ & 2,60 & 1,80 & 1,30 & 1,00 & 3,90 & 3,00 & 16,63 & 15,80 & $-0,04$ & 0,67 & 0,30 & 0,37 \\
\hline $\mathrm{Mg}^{(3)}, \mathrm{cmol}_{\mathrm{c}} \mathrm{dm}^{-3}$ & $1,01 \mathrm{a}$ & $0,69 \mathrm{~b}$ & 1,00 & 0,70 & 0,60 & 0,40 & 1,60 & 1,30 & 21,64 & 22,05 & 0,42 & 0,65 & 0,04 & 0,58 \\
\hline $\mathrm{S}^{(4)}, \mathrm{mg} \mathrm{dm}^{-3}$ & $12,31 \mathrm{a}$ & $5,38 \mathrm{~b}$ & 11,80 & 5,00 & 6,00 & 2,00 & 24,00 & 13,00 & 35,93 & 42,86 & 0,57 & 0,89 & $-0,24$ & 0,65 \\
\hline \multicolumn{15}{|c|}{ Fazenda São Luiz de Jaborandi - textura média } \\
\hline $\mathrm{P}, \mathrm{mg} \mathrm{dm}^{-3}$ & 13,27 a & $12,62 \mathrm{~b}$ & 10,80 & 11,80 & 4,20 & 2,90 & 34,30 & 24,20 & 55,76 & 48,73 & 1,15 & 0,27 & 0,70 & $-0,55$ \\
\hline $\mathrm{K}, \mathrm{mg} \mathrm{dm}{ }^{-3}$ & $65,02 \mathrm{a}$ & $34,78 \mathrm{~b}$ & 62,40 & 32,50 & 19,50 & 15,60 & 130,20 & 69,40 & 38,99 & 33,65 & 0,41 & 0,74 & $-0,16$ & $-0,26$ \\
\hline $\mathrm{Ca}, \mathrm{cmol}_{\mathrm{c}} \mathrm{dm}^{-3}$ & $1,15 \mathrm{a}$ & $1,00 \mathrm{a}$ & 1,10 & 1,10 & 0,60 & 0,40 & 1,60 & 1,60 & 16,24 & 19,03 & $-0,01$ & $-0,30$ & $-0,03$ & 0,05 \\
\hline $\mathrm{Mg}, \mathrm{cmol}_{\mathrm{c}} \mathrm{dm}^{-3}$ & $0,35 \mathrm{a}$ & $0,29 \mathrm{a}$ & 0,40 & 0,30 & 0,14 & 0,10 & 0,60 & 0,60 & 23,94 & 20,81 & 0,03 & 0,52 & 0,50 & 0,81 \\
\hline $\mathrm{S}, \mathrm{mg} \mathrm{dm}^{-3}$ & $7,03 \mathrm{~b}$ & $7,67 \mathrm{a}$ & 7,00 & 7,00 & 4,05 & 4,00 & 12,00 & 12,00 & 19,02 & 20,98 & 0,26 & 0,66 & 0,53 & 2,23 \\
\hline
\end{tabular}

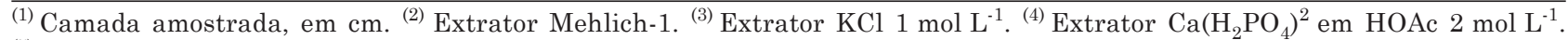

${ }^{(5)}$ Médias seguidas por letras distintas, na linha, diferem entre si a $5 \%$ pelo teste t.

adubações em superfície, a lanço ou nas linhas de cultivo que tendem à formação de gradiente de concentração superficial após quatro a seis anos de cultivo. Além disso, elementos menos móveis no solo, como $\mathrm{P}$, de maneira geral, formam maiores gradientes de concentração (Eltz et al., 1989; Klepker \& Anghinoni, 1995; Bayer \& Mielniczuk, 1997; Amaral \& Anghinoni, 2001; Falleiro et al., 2003). A exceção foi o S, pois na FSR, de solo muito argiloso, seus teores foram maiores nos primeiros centímetros do solo, ocorrendo o inverso na FSLJ, de solo textura média. Segundo Caires et al. (1998), a velocidade com que o sulfato se movimenta varia de acordo com a textura do solo, devendo ser mais lenta naqueles com maior teor de argila, como na FSR.

De acordo com a classificação do coeficiente de variação (CV) proposta por Warrick \& Nielsen (1980), todas as variáveis, com exceção do $\mathrm{P}$, na FSR, na camada de $0-10 \mathrm{~cm}$, que mostrou CV alto (> $60 \%$ ), apresentaram CV médios (12,1 a 60 \%) (Quadro 1). A grande variabilidade horizontal encontrada para os teores de $\mathrm{P}$ e $\mathrm{K}$ concorda com os resultados obtidos por Santos \& Vasconcellos (1987), Souza (1992), Souza et al. (1997), Salviano et al. (1998) e Schlindwein \& Anghinoni (2000). Segundo muitos desses autores, os fertilizantes fosfatados e potássicos são aplicados anualmente e provocam maior variabilidade devido à localização dos fertilizantes nas linhas de semeadura, que são mantidas por meio dos cultivos.

No caso do K, foi observada maior variabilidade dos seus teores na FSLJ. A influência do sistema de manejo na distribuição desse elemento é dependente das características do solo. Souza (1992) encontrou elevada variabilidade nos teores de K em áreas muito pequenas e, em outras, observou distribuição normal, com menor variabilidade, porém ainda considerada alta. Santos \& Vasconcellos (1987) também encontraram resultados bastante variáveis, mostrando que o K no solo não apresenta padrão uniforme de comportamento. No caso do S, foi verificada também grande variabilidade horizontal, maior que a do K, na FSR e variabilidade média na FSLJ. São poucos os dados na literatura sobre variabilidade de $\mathrm{S}$ em sistema plantio direto. Sob esse sistema, Trevisan et al. (2008) encontraram CV de $32,1 \%$ para os teores desse elemento na camada superficial em solo muito argiloso e menores entre 10 e $20 \mathrm{~cm}$, assim como neste trabalho. Maiores variações nos teores de $\mathrm{S}$ também podem ser explicadas pelo manejo semelhante ao do $\mathrm{P}$ e ao do $\mathrm{K}$ e pela interação do $\mathrm{S}$ com a fase mineral do solo muito argiloso, pois no de textura média (FSLJ) a variabilidade desse elemento foi menor, assim como seus teores (Quadro 1). No solo, o $\mathrm{S}$ interage com os grupos funcionais dos coloides orgânicos e inorgânicos. Segundo Parfitt \& Smart (1978), solos mais argilosos e com teores elevados de óxidos de ferro apresentam alta capacidade de retenção de $\mathrm{S}$, e sua movimentação no perfil é mais lenta nesses solos que nos arenosos e de textura média.

Os valores máximos e mínimos foram maiores na camada de $0-10 \mathrm{~cm}$, refletindo o que já foi discutido para os maiores teores dos nutrientes encontrados nessa camada (Quadro 1). Quando se analisa a amplitude entre os valores mínimos e máximos, podese ter uma noção da variabilidade dos dados. Souza 
(1992) observou correlação diretamente proporcional entre essa amplitude e os respectivos coeficientes de variação. No presente trabalho, os menores coeficientes de variação foram observados para Ca e os maiores para P, ambos na FSR (Quadro 1). A amplitude dos dados representou bem seus respectivos coeficientes de variação. Por exemplo, o valor máximo do Ca encontrado na camada de $0-10 \mathrm{~cm}$ (menor CV) foi três vezes maior que o valor mínimo; para $\mathrm{P}$ (maior CV), por sua vez, na mesma camada, foi 8,1 vezes.

O coeficiente de assimetria é utilizado para caracterizar como e quanto a distribuição de frequências se afasta da simetria. Se o valor encontrado para esse coeficiente for zero, a distribuição é simétrica; se for positivo, a distribuição é assimétrica à direita; e se for negativo, é assimétrica à esquerda. Na FSR, a maioria das variáveis apresentou distribuição de frequências assimétrica à direita (+): apenas o $\mathrm{Ca}$, na camada de $0-10 \mathrm{~cm}$, mostrou distribuição de frequências assimétrica à esquerda (-). $\mathrm{Na}$ FSLJ, com exceção do Ca, nas duas profundidades, que apresentou distribuição de frequências assimétrica à esquerda (-), todas as variáveis apresentaram distribuição de frequências assimétrica à direita (+). O maior valor de coeficiente de assimetria positivo foi do $\mathrm{P}(1,15)$ e o menor do $\mathrm{Mg}(0,03)$, ambos na camada de $0-10 \mathrm{~cm}$, na FSLJ, refletindo os respectivos coeficientes de variação. Dos três coeficientes negativos encontrados, os maiores e os menores valores foram os do Ca, na FSLJ, nas profundidades de 0-10 (-0,01) e $10-20 \mathrm{~cm}(-0,30)$, respectivamente. Foi verificado maior número de coeficientes de assimetria negativos para a profundidade de $0-10 \mathrm{~cm}$.

Segundo Snedecor \& Cochran (1967), os valores de assimetria e de curtose para a distribuição normal devem ser de 0 e 3 , respectivamente, mas o programa $\mathrm{GS}^{+}$utiliza como valor de comparação da curtose o $0 \mathrm{e}$ não o 3. Portanto, observa-se que a grande maioria dos dados aproximou-se da distribuição normal, excetuando-se o S , nos 10-20 cm, na FSLJ.

Para a maioria das variáveis, apesar de terem sido encontradas distribuições assimétricas, verificou-se, por indícios como valores médios e medianos semelhantes e coeficientes de assimetria e curtose próximos a zero, que as medidas de tendência central não são dominadas por valores atípicos na distribuição e que se aproximam de uma distribuição normal. Assim, segundo Cambardella et al. (1994), pode-se considerar que os dados estão adequados para aplicação da geoestatística.

A análise geoestatística, efetuada por meio dos semivariogramas, mostrou que todas as variáveis apresentaram dependência espacial na camada de 0$10 \mathrm{~cm}$. Na camada de 10-20 cm, na FSR, apenas P e S não apresentaram dependência espacial, e na FSLJ, apenas K, Mg e S (Quadro 2). Quando a variável estudada é independente espacialmente, o seu $\mathrm{C}_{0}$ (efeito pepita) é igual a $\mathrm{C}_{1}+\mathrm{C}_{0}$ (patamar), conhecido como efeito pepita puro (EPP). O EPP é importante e indica distribuição casual, ou seja, variabilidade não explicada ou variação não detectada, e pode ocorrer

Quadro 2. Estimativa dos parâmetros dos modelos dos semivariogramas ajustados de teores de macronutrientes em Latossolos com texturas distintas cultivados no sistema plantio direto

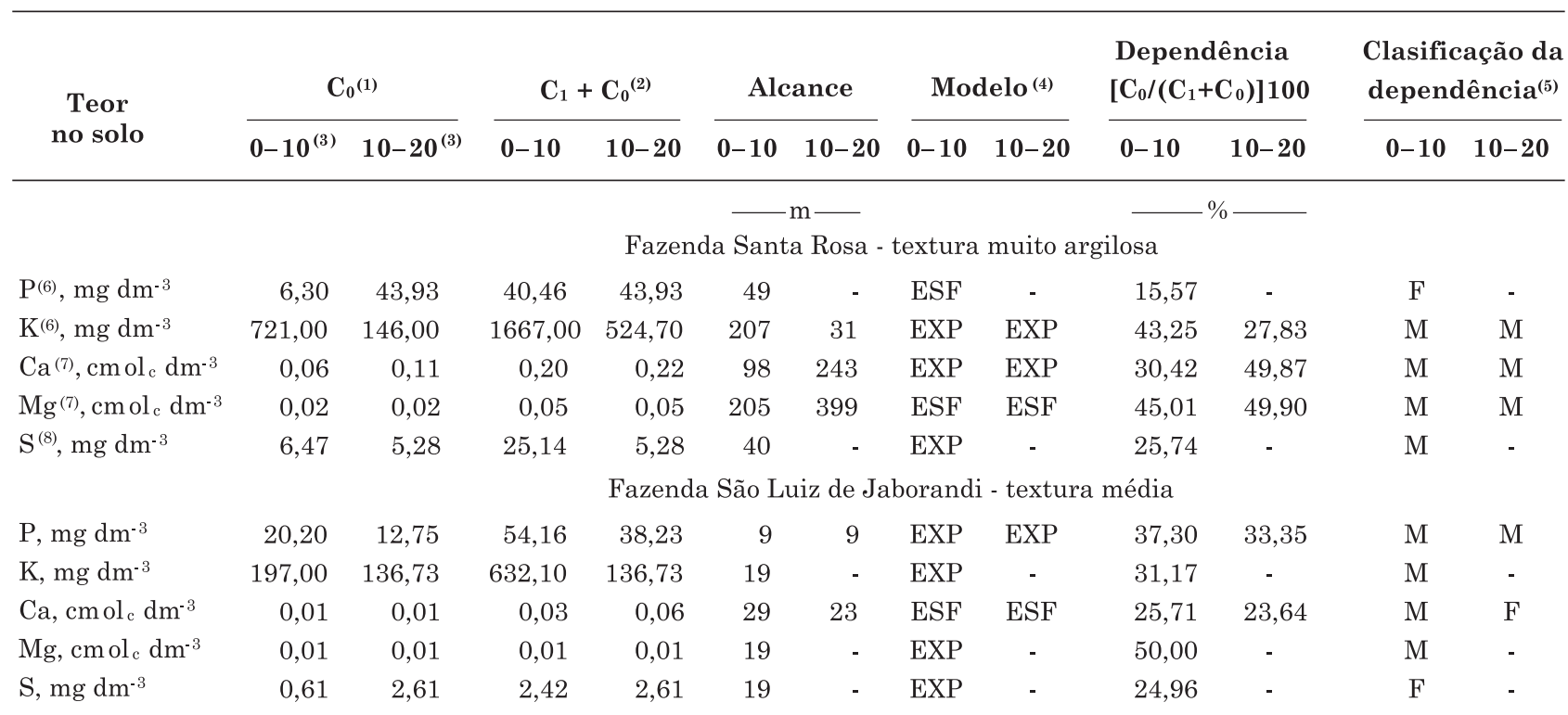

${ }^{(1)} \mathrm{C}_{0}$ representa o efeito pepita. ${ }^{(2)} \mathrm{C}_{1}+\mathrm{C}_{0}$ representa o patamar. ${ }^{(3)}$ Modelo: ESF: esférico; EXP: exponencial. ${ }^{(4)} \mathrm{F}$ : forte e $\mathrm{M}$ :

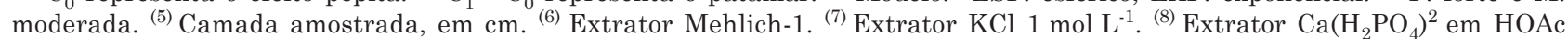
$2 \mathrm{~mol} \mathrm{~L}^{-1}$. 
devido a erros de medidas, erros de amostragem, ou microvariação não detectada, considerando ser o espaçamento de amostragem utilizado maior que o necessário para detectar dependência espacial (Cambardella et al., 1994).

Quanto aos semivariogramas, foram ajustados apenas os modelos exponencial (dez variáveis) e esférico (cinco variáveis). Na FSR, ajustou-se o modelo exponencial para $\mathrm{K}(0-10$ e 10-20 cm), Ca (0-10 e 10 $20 \mathrm{~cm})$ e $\mathrm{S}(0-10 \mathrm{~cm})$ e esférico para $\mathrm{P}(0-10 \mathrm{~cm})$ e $\mathrm{Mg}$ (0-10 e 10-20 cm). Na FSLJ, o modelo exponencial foi ajustado para $\mathrm{P}(0-10$ e $10-20 \mathrm{~cm}), \mathrm{Mg}(0-10 \mathrm{~cm})$ e S $(0-10 \mathrm{~cm})$ e o esférico para $\mathrm{K}(0-10 \mathrm{~cm})$ e Ca $(0-10$ e 10-20 cm) (Quadro 2). Esses dois modelos teóricos, exponencial e esférico, são os mais comuns ajustados às variáveis de solo (Trangmar et al.,1985; Cambardella et al., 1994; Salviano et al., 1998; Zanão Júnior, 2004; Zanão Júnior et al., 2007).

Um parâmetro importante no estudo dos semivariogramas é o alcance, que indica a distância máxima em que os pontos amostrais estão correlacionados entre si (Vieira et al., 1983), ou seja, determinações realizadas a distâncias maiores que o alcance têm distribuição aleatória e, por isso, são independentes entre si. É uma medida importante para planejamento e avaliação experimental, podendo auxiliar na definição de procedimentos amostrais (Webster, 1985), tendo aplicação direta no plano de amostragem na agricultura de precisão. Os alcances foram menores na FSLJ, que possui solo com textura média, variando de 9 a $29 \mathrm{~m}$. Na FSR, os alcances variaram de 31 a $399 \mathrm{~m}$. O menor valor de alcance foi de $9 \mathrm{~m}$ para $\mathrm{P}$, nas duas profundidades, e o maior, de 399 m, para Mg, na FSR (10-20 cm) (Quadro 2). $\mathrm{O}$ valor de alcance também variou com a profundidade de coleta da amostra. Na FSR, o alcance do $\mathrm{K}$ foi quase sete vezes maior na profundidade de $0-10 \mathrm{~cm}$, e, no caso do Ca e do $\mathrm{Mg}$, foi menor quase 2,5 e 2,0 vezes, respectivamente, em relação à profundidade de $10-20 \mathrm{~cm}$. Nota-se que, se for adotada a geoestatística no esquema de amostragem, o número de amostras a serem coletadas em cada propriedade e em cada camada será distinto, possivelmente coletando-se um número menor de amostras na FSR, devido aos maiores valores do alcance apresentados por todas as variáveis nessa propriedade (solo de textura muito argilosa). Foi verificado também que, além da variabilidade vertical, há variabilidade horizontal entre as camadas amostradas, visto que os valores de alcance para uma mesma variável foram distintos entre elas.

Para analisar o grau de dependência espacial dos atributos em estudo, utilizou-se a classificação proposta por Cambardella et al. (1994). A análise do efeito pepita dos atributos químicos do solo revelou que houve predominância de dependência espacial moderada nas duas propriedades e camadas. Houve três dependências espaciais consideradas fortes apenas para $\mathrm{P}(0-10 \mathrm{~cm})$ na FSR, e na FSLJ, para $\mathrm{S}(0-10 \mathrm{~cm})$ e Ca (10-20 cm) (Quadro 2). Isso demonstra que os semivariogramas explicam a maior parte da variância dos dados. Segundo Cambardella et al. (1994), atribuise a forte dependência espacial das características químicas e físicas do solo aos fatores intrínsecos, e a fraca dependência, aos extrínsecos.

Os resultados obtidos devem ser considerados na definição de planos de amostragem do solo e no manejo da adubação das áreas em questão por meio da análise do alcance e da variabilidade horizontal e vertical dos atributos químicos estudados. Um maior número de amostras deve ser retirado na Fazenda São Luiz de Jaborandi, de solo com textura média, pois ela apresentou menores valores de alcance e, de maneira geral, maior variabilidade espacial.

Os mapas de isolinhas obtidos por meio da interpolação dos dados, pelo método da krigagem, são fundamentais na agricultura de precisão, pois eles são posteriormente analisados e trabalhados com a finalidade de planejar e praticar adubações mais exatas e com menor relação custo/benefício. Nesses mapas, pode-se visualizar na área amostrada a distribuição espacial dos teores dos nutrientes avaliados. O conhecimento dos valores do alcance, aliado à visualização das localizações das áreas nos mapas de isolinhas, é importante para o planejamento do manejo da fertilidade do solo. Os mapas de isolinhas mostramse mais homogêneos para $\mathrm{Ca}$ e $\mathrm{Mg}$, que apresentam os menores coeficientes de variação (Figuras 1 e 2). Além disso, fica evidente o fato de o manejo do solo (adubação e calagem) interferir na distribuição espacial de seus atributos químicos. Pelo fato de Ca e $\mathrm{Mg}$ serem aplicados via calcário, os mapas de isolinhas dos teores desses elementos mostraram-se semelhantes.

Foram feitos mapas de isolinhas conforme as classes de fertilidade do solo, de acordo com a classificação proposta por Alvarez V. et al. (1999) para os solos de Minas Gerais. Para apenas exemplificar, foram elaborados mapas somente para os teores dos nutrientes na camada de 0-10 cm, na FSR (Figura 3). Fazer os mapas de acordo com as classes de fertilidade do solo propostas para cada Estado ou região é mais lógico do que fazê-los de acordo com os intervalos propostos pelos programas que os geram. Sugere-se que todos os mapas gerados em trabalhos que estudem a variabilidade espacial dos atributos químicos dos solos sejam assim produzidos. No caso da FSR, podese observar que os teores dos elementos avaliados estão em apenas duas classes, excetuando-se os do $\mathrm{P}$, que estão em três classes. Assim, com o auxílio desses mapas, faz-se a recomendação de calagem e adubação e seu manejo de modo que se alcance apenas uma classe: a mais adequada para a cultura a ser implantada. A partir desse momento a área pode ser considerada homogênea, e menos amostras de solo devem ser coletadas para representar a fertilidade do solo dela. 

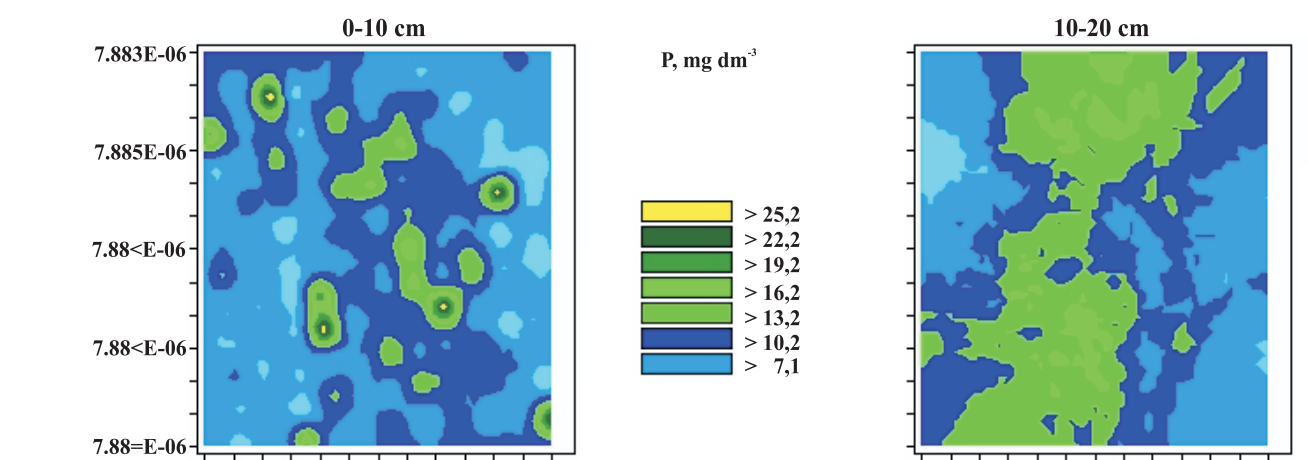

$\mathrm{P}, \mathrm{mg} \mathrm{dm}^{-3}$
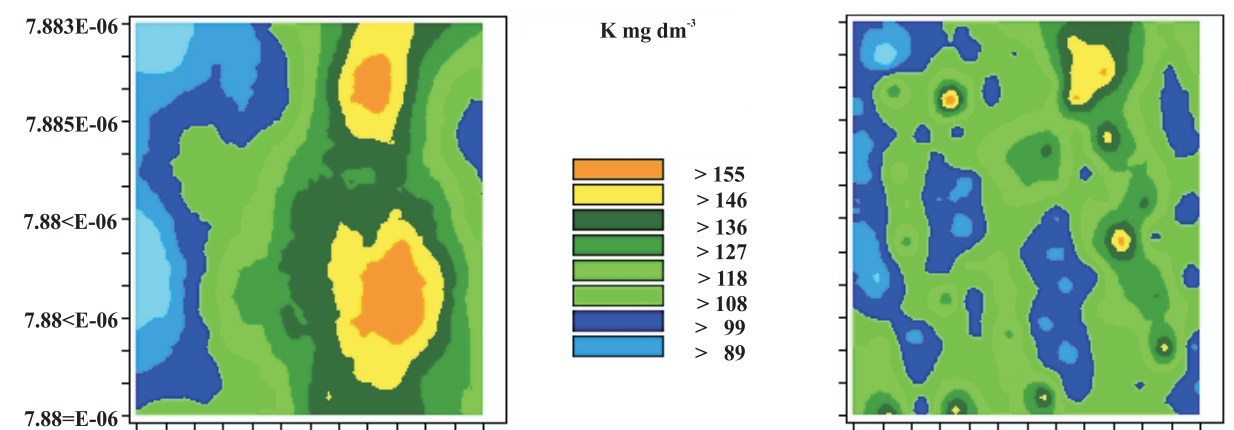

$\mathrm{K} \mathrm{mg} \mathrm{dm}{ }^{-3}$

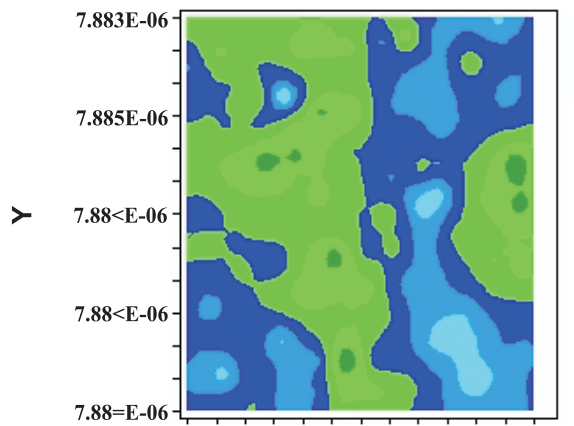

Ca, $\mathrm{cmol}_{\mathrm{c}} \mathrm{dm}^{-3}$
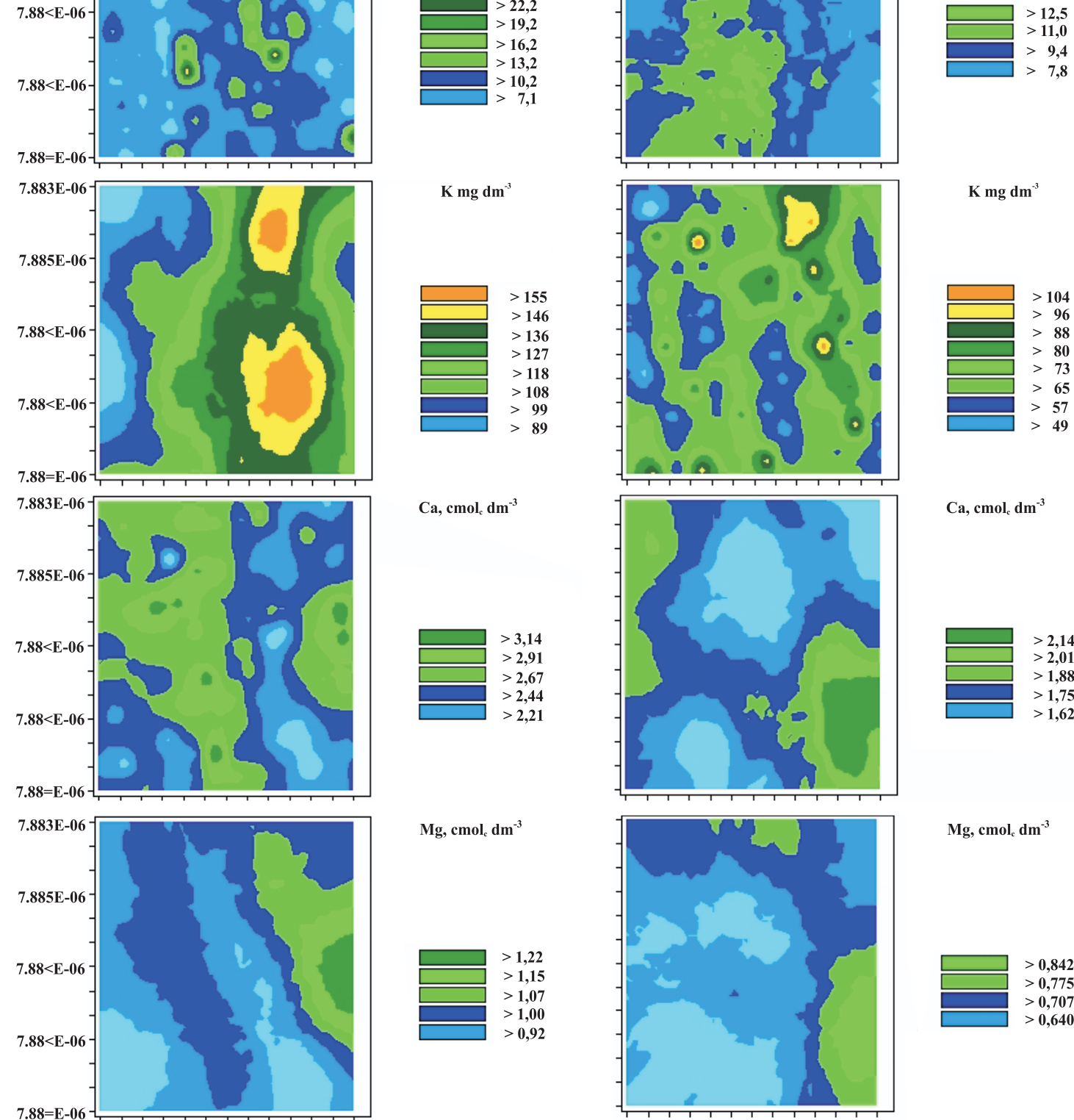

$\mathrm{Mg}, \mathrm{cmol}_{\mathrm{c}} \mathrm{dm}^{-3}$

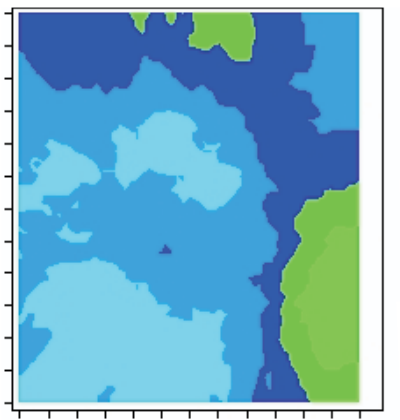

$\mathrm{Mg}, \mathrm{cmol}_{\mathrm{c}} \mathrm{dm}^{-3}$

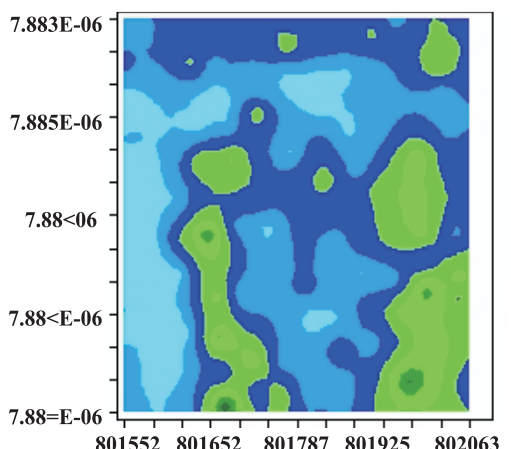

$\mathrm{X}$
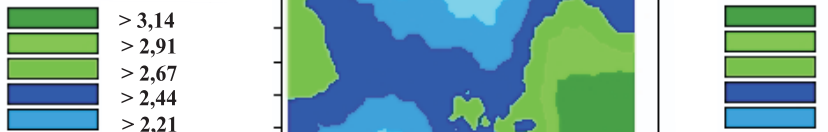

$>2,14$

$>2,01$

$>1,88$

$>1,75$
$>1,62$

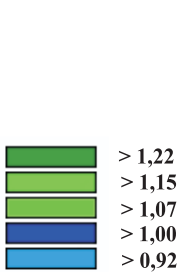

$S, \mathbf{m g ~ d m}^{-3}$

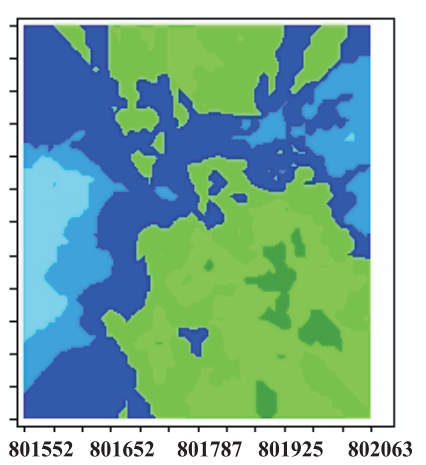

$\mathrm{S}, \mathrm{mg} \mathrm{dm}^{-3}$

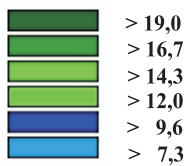

$X$
Figura 1. Mapas de isolinhas de teores de macronutrientes em diferentes camadas de um Latossolo Vemelho textura muito argilosa, sob sistema plantio direto (Fazenda Santa Rosa). 

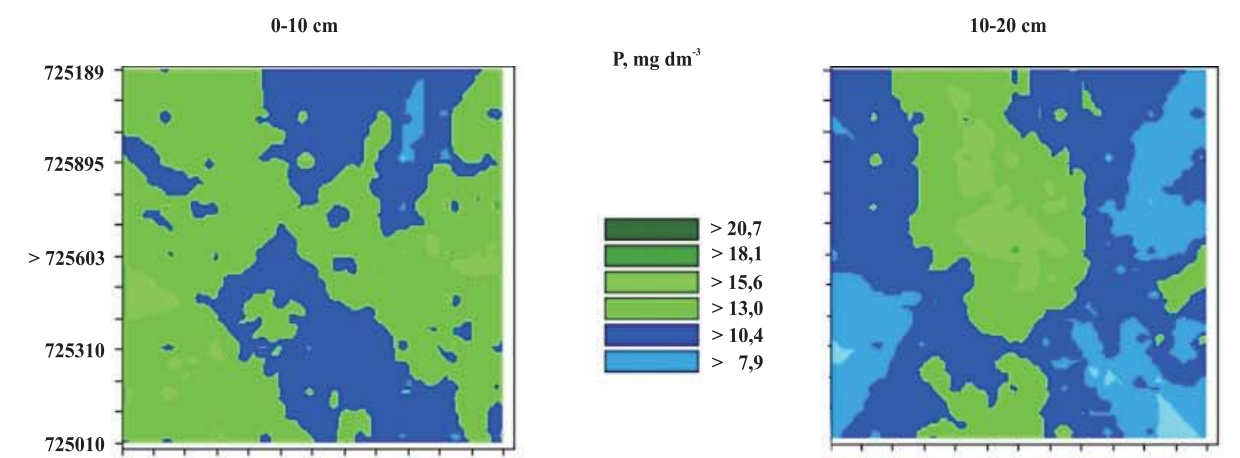

$\mathbf{P}, \mathrm{mg} \mathrm{dm}^{-3}$
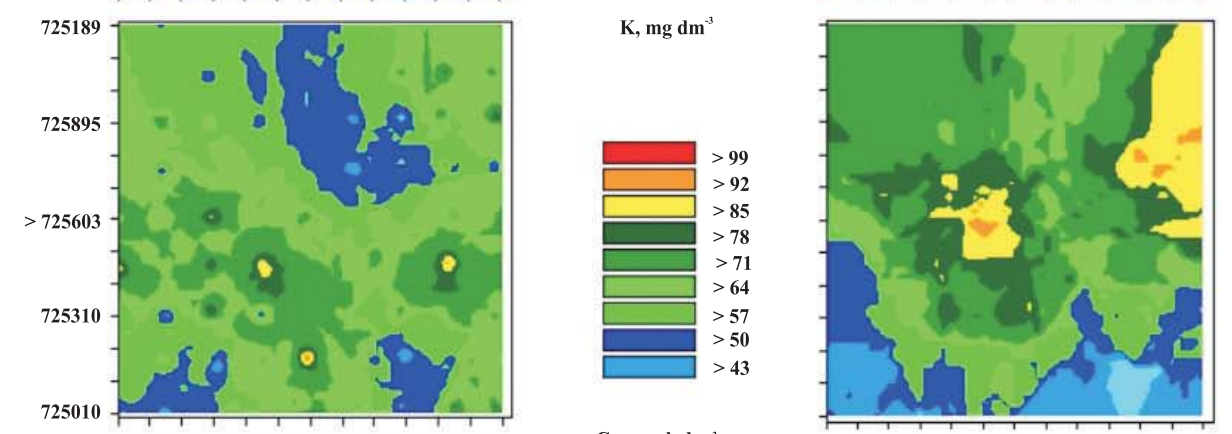

$\mathrm{K}, \mathbf{m g d m ^ { - 3 }}$
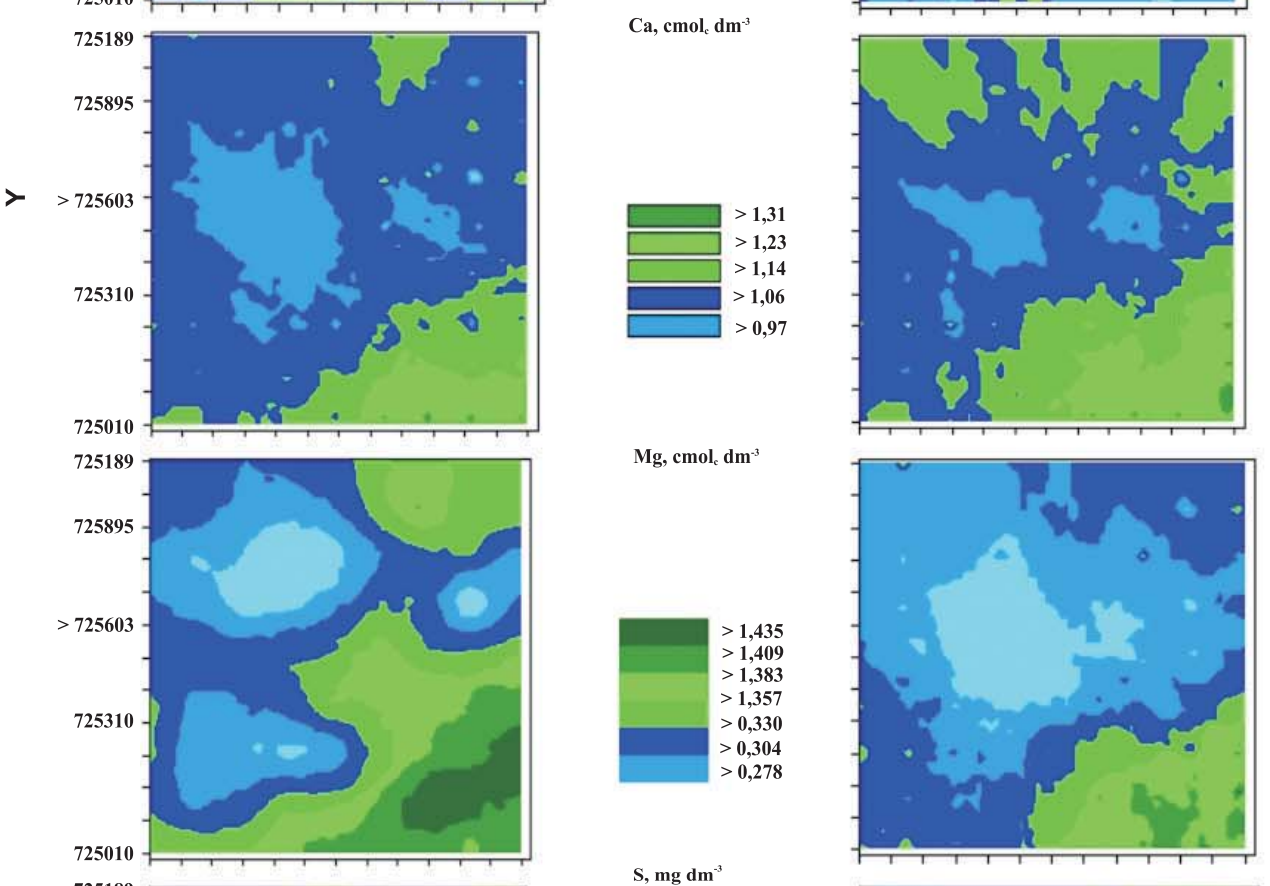

$\mathrm{Mg}, \mathrm{cmol}_{\mathrm{c}} \mathbf{d m}^{-3}$
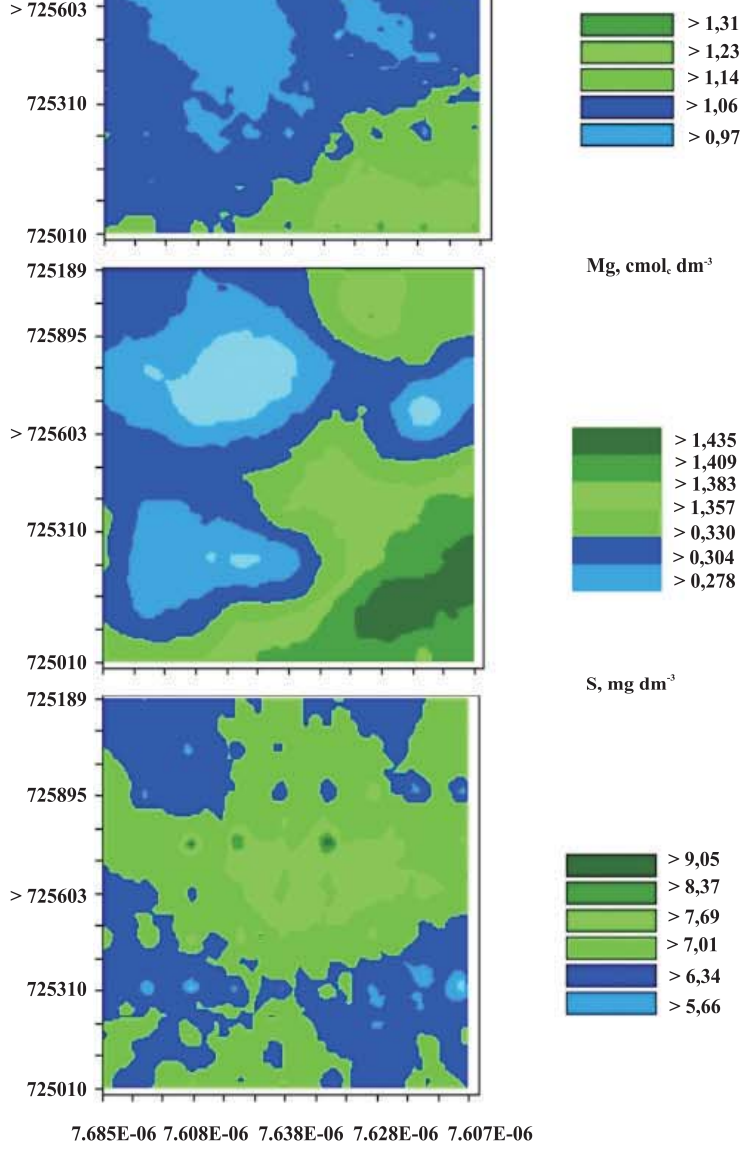

S, $\mathbf{m g ~ d m}^{-3}$

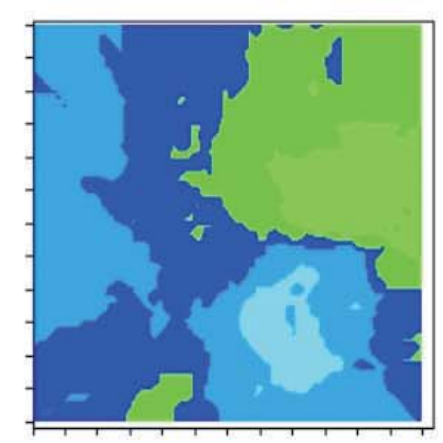

$\mathrm{S}, \mathrm{mg} \mathrm{dm}^{-3}$

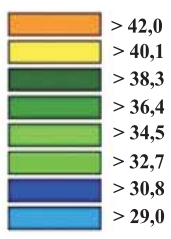

$\mathrm{Ca}, \mathrm{cmol}_{\mathrm{c}} \mathrm{dm}^{-3}$
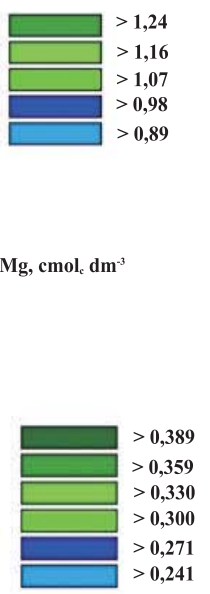

7.685E-06 7.608E-06 7.638E-06 7.628E-06 7.607E-06

$\mathrm{X}$

Figura 2. Mapas de isolinhas de teores de macronutrientes em diferentes camadas de um Latossolo Vemelho textura média, sob sistema plantio direto (Fazenda São Luiz de Jaborandi). 


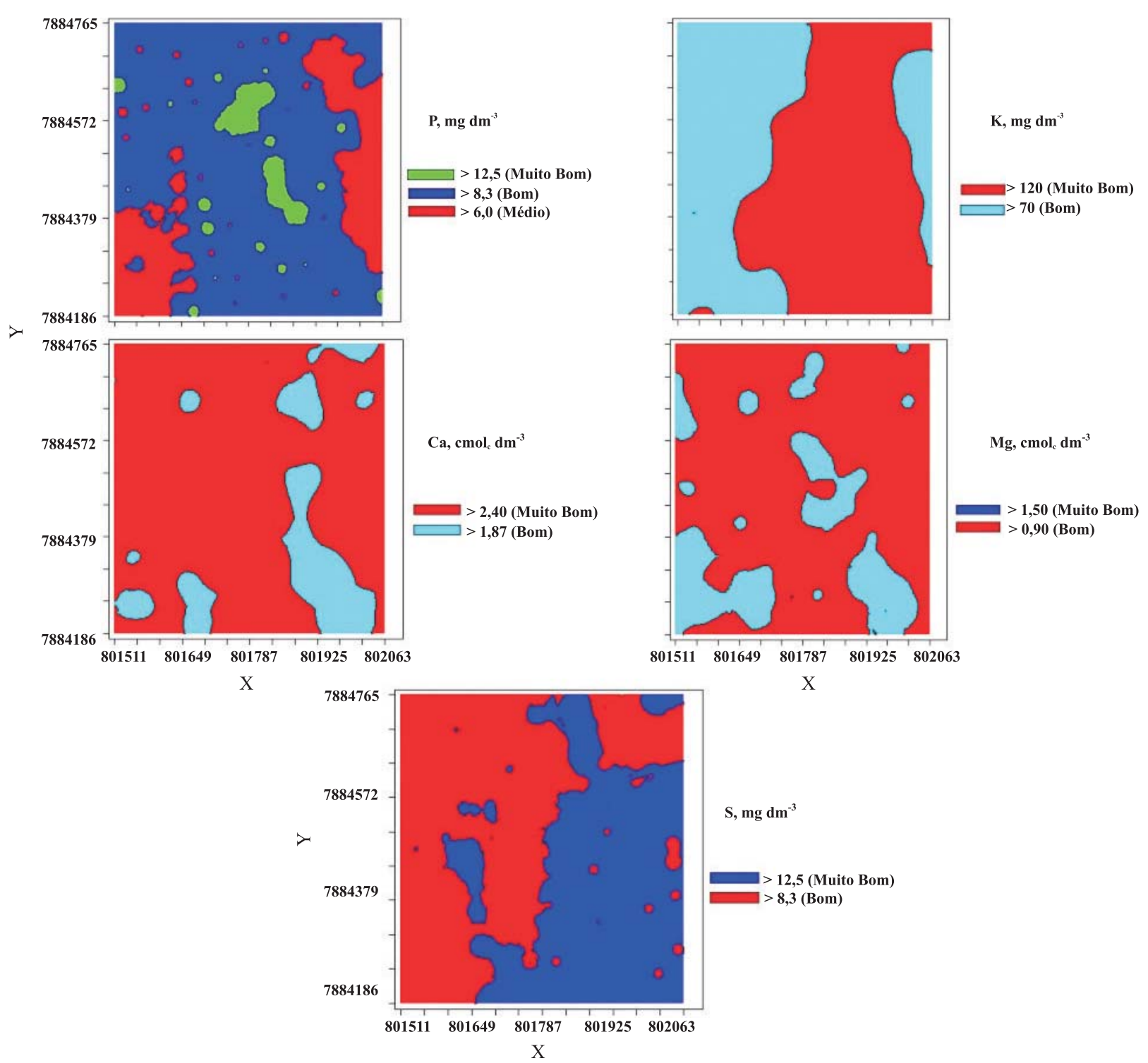

Figura 3. Mapas de isolinhas baseados nas classes de teores de macronutrientes (segundo Alvarez V. et al., 1999), na camada de 0-10 cm, em Latossolo Vemelho textura muito argilosa, sob sistema plantio direto (Fazenda Santa Rosa).

\section{CONCLUSÕES}

1. A dependência espacial variou conforme a textura do solo e a profundidade de coleta da amostra.

2. Na camada de $0-10 \mathrm{~cm}$, nos dois solos estudados, de maneira geral, foi verificada maior variabilidade espacial nos teores dos nutrientes avaliados $(\mathrm{P}, \mathrm{K}, \mathrm{Ca}$, $\mathrm{Mg}$ e S) em relação à camada de 10-20 cm.

3. Os valores do alcance foram menores no Latossolo de textura média do que no de textura argilosa.

4. A análise da dependência espacial mostrou que, nos dois solos e nas duas camadas, a maioria dos nutrientes estudados possui moderada correlação espacial, com semivariogramas ajustados aos modelos exponencial e esférico, sendo o primeiro mais frequente.

5. Além da variabilidade vertical, há também variabilidade horizontal entre as profundidades, visto que para um mesmo nutriente $o$ alcance foi diferente entre as camadas amostradas.

\section{AGRADECIMENTOS}

À Fapemig, pela bolsa de iniciação científica e pelo financiamento concedidos; e aos técnicos do Laboratório de Análise de Solos do Instituto de Ciências Agrárias da Universidade Federal de Uberlândia, pelo auxílio. 


\section{LITERATURA CITADA}

ALVAREZ V., V.H.; NOVAIS, R.F.; BARROS, N.F.; CATARUTTI, R.B. \& LOPES, A.S. Interpretação dos resultados das análises de solos. In: RIBEIRO, A.C.; GUIMARÃES, P.T.G. \& ALVAREZ V., V.H., eds. Recomendações para o uso de corretivos e fertilizantes em Minas Gerais, $5^{\text {a }}$ Aproximação. Viçosa, MG, Comissão de Fertilidade do Solo do Estado de Minas Gerais, 1999. p.25-32.

ALVAREZ V., V.H.; DIAS, L.E.; RIBEIRO, F.S.; SOUZA, R.B. \& FONSECA, C.A. Métodos de análises de enxofre em solos e plantas. Viçosa, MG, Universidade Federal de Viçosa, 2001. 131p.

ALVES, V.M.C.; VASCONCELLOS, C.A.; FREIRE, F.M.; PITTA, G.V.E.; FRAÇA, G.E.; RODRIGUES FILHO, A.; ARAÚJO, J.M.; VEIRA, J.R. \& LOUREIRO, J.E. Milho. In: RIBEIRO, A.C.; GUIMARÃES, P.T.G. \& ALVAREZ V., V.H., eds. Recomendações para o uso de corretivos e fertilizantes em Minas Gerais, $5^{\mathrm{a}}$ Aproximação. Viçosa, MG, Comissão de Fertilidade do Solo do Estado de Minas Gerais, 1999. p.314-316.

AMARAL, A.S. \& ANGHINONI, I. Alterações de parâmetros químicos do solo pela reaplicação superficial de calcário no sistema plantio direto. Pesq. Agropec. Bras., 36:695$702,2001$.

BAYER, C. \& MIELNICZUK, J. Características químicas do solo afetadas por métodos de preparo e sistemas de cultura. R. Bras. Ci. Solo, 21:105-112, 1997.

BHATTI, A.U.; MULLA, D.J. \& FRAZIER, B.E. Estimation of soil properties and wheat yields on complex eroded hills using geoestatistics and thematic mapper images. Rem. Sens. Environ. 37:181-191, 1991.

BURGESS, T.M. \& WEBSTER, R. Optimal interpolation and isaritimic mapping of soil properties: I. The semivariogram and punctual kriging. J. Soil Sci., 31:315-331, 1980.

BURROUGH, P.A.; VAREKAMP, C. \& SKIDMORE, A.K. Using public domain geostatistical and GIS software for spatial interpolation. Photog. Eng. Rem. Sen., 62:845-854, 1996.

CAIRES, E.F.; CHUEIRI, W.A.; MADRUGA, E.F. \& FIGUEIREDO, A. Alterações de características químicas do solo e resposta da soja ao calcário e gesso aplicados na superfície em sistema de cultivo sem preparo de solo. R. Bras. Ci. Solo, 22:27-34, 1998.

CAMBARDELLA, C.A.; MOORMAN, T.B.; NOVAK, J.M.; PARKIN, T.B.; KARLEN, D.L.; TURCO, R.F. \& KONOPKA, A.E. Field scale variability of soil properties in Central Iowa soils. Soil Sci. Soc. Am. J., 58:1501-1511, 1994.

CORÁ, J.E.; ARAUJO, A.V.; PEREIRA, G.T. \& BERALDO, J.M.G. Variabilidade espacial de atributos do solo para adoção do sistema de agricultura de precisão na cultura de cana-de-açúcar. R. Bras. Ci. Solo, 28:1013-1021, 2004.

ELTZ, F.L.P.; PEIXOTO, R.T.G. \& JASTER, F. Efeitos de sistemas de preparo do solo nas propriedades físicas e químicas de um Latossolo Bruno álico. R. Bras. Ci. Solo, 13:259-267, 1989.
EMPRESA BRASILEIRA DE PESQUISA AGROPECUÁRIA EMBRAPA. Manual de métodos de análise de solo. 2.ed. Rio de Janeiro, Centro Nacional de Pesquisa de Solos, 1997. 212p.

FALLEIRO, R.M.; SOUZA, C.M.; SILVA, C.S.W.; SEDIYAMA, C.S.; SILVA, A.A. \& FAGUNDES, J.L. Influência dos sistemas de preparo nas propriedades químicas e físicas do solo. R. Bras. Ci. Solo, 27:1097-1104, 2003.

GAMMA DESIGN SOFTWARE. Geoestatistics for the environmental sciences. 5.ed. 1 for Windows, Michigan, 2000.

KLEPKER, D. \& ANGHINONI, I. Características físicas e químicas do solo afetadas por métodos de preparo e modos de adubação. R. Bras. Ci. Solo, 19:395-401, 1995.

LITTLE, T.M. \& HILLS, F.J. Agricultural experimentation. New York, John Wiley \& Sons, 1978. 350p.

MALZER, G.L. Is precision farming good for society? Better Crops, 80:6-8, 1996.

MONTANARI, R.; PEREIRA, G.T.; MARQUES JÚNIOR, J.; SOUZA, Z.M.; PAZETO, R.J. \& CAMARGO, L.A. Variabilidade espacial de atributos químicos em Latossolo e Argissolos. Ci. Rural, 38: 1266-1272, 2008.

MUZILLI, O. Influência do sistema de plantio direto, comparado ao convencional, sobre a fertilidade da camada arável do solo. R. Bras. Ci. Solo, 7:95-102, 1983.

ORLANDO FILHO, J. \& RODELLA, A. A análise química do solo e recomendação de adubação. In: ORLANDO FILHO, J. coord. Nutrição e adubação da cana-de-açúcar no Brasil. Piracicaba, Instituto do Açúcar e do Álcool/Planalsucar, 1983. p.155-178.

PARFITT, R.L. \& SMART, R.S.C. Mechanism of sulfate adsorption on iron-oxides. Soil Sci Soc. Am. J., 42:48-50, 1978.

SALVIANO, A.A.C.; VIEIRA, S.R. \& SPAROVEK, G. Variabilidade espacial de atributos de solo e de Crotalaria juncea L. em área severamente erodida. R. Bras. Ci. Solo, $22: 115-122,1998$

SANTOS, H.L.; \& VASCONCELOS, C.A. Determinação do número de amostras de solo para análise química em diferentes condições de manejo. R Bras Ci Solo, 11:97$100,1987$.

SCHLINDWEIN, J.A. \& ANGHINONI, I. Variabilidade horizontal de atributos de fertilidade e amostragem do solo no sistema plantio direto. R. Bras. Ci. Solo, 24:85-91, 2000.

SNEDECOR, G.W. \& COCHRAN, W.G. Statistical methods. 6.ed. Ames, Iowa State University, 1967. 593p.

SOUZA, L.S.; COGO, N.P. \& VIEIRA, S.R. Variabilidade de propriedades físicas e químicas do solo em um pomar cítrico. R. Bras. Ci. Solo, 21:367-372, 1997.

SOUZA, L.S. Variabilidade espacial do solo em sistemas de manejo. Porto Alegre, Universidade Federal do Rio Grande do Sul, 1992. 162p. (Tese de Doutorado)

TRANGMAR, B.B.; YOST, R.S.; WADE, M.K. \& UEHARA, G. Applications of geostatistics to spatial studies of soil properties. Adv. Agron., 38:45-94, 1985. 
TREVISAN, L.R.; LANA, R.M.Q.; ZANÃO JÚNIOR, L.A.; LACERDA, Z.C. \& GUIMARÃES, E.C. Variabilidade vertical de $\mathrm{pH}$, bases e enxofre em Latossolo Vermelho cultivado sob sistema plantio direto e cultivo mínimo. Horiz. Cient., 7:1-11, 2008.

VIEIRA, S.R.; HATFIELD, J.L.; NIELSEN, D.R. \& BIGGAR, J.W. Geostatistical theory and application to variability of some agronomical properties. Hilgardia, 51:1-75, 1983.

WARRICK, A.W. \& NIELSEN, D.R. Spatial variability of soil physical properties in the field. In: HILLEL, D Applications of soil physics. New York, Academic, 1980. Part 2. p.319-44.
WEBSTER, R. Quantitative spatial analysis of soil in the field. In: STEWART, B.A., ed. Advance in soil science. New York, Springer-Verlag, 1985. p.1-70.

ZANÃO JÚNIOR, L.A. Variabilidade espacial de atributos químicos de um solo sob sistema plantio direto. Uberlândia, Universidade Federal de Uberlândia, 2004. 51p. (Monografia de conclusão de curso)

ZANÃO JÚNIOR, L.A.; LANA, R.M.Q. \& GUIMARÃES, E.C. Variabilidade espacial do $\mathrm{pH}$, teores de matéria orgânica e micronutrientes em profundidade em um Latossolo Vermelho sob semeadura direta. Ci. Rural, 37:1000-1007, 2007. 